\title{
The impact of comorbid allergic airway disease on the severity and mortality of COVID-19: a systematic review and meta-analysis
}

\author{
Wei Ming ${ }^{1} \odot$ - Jingjing Zuo ${ }^{1}$ Jibo Han ${ }^{1} \cdot$ Jinhui Chen $^{1}$
}

Received: 9 June 2021 / Accepted: 5 September 2021 / Published online: 14 September 2021

(c) The Author(s), under exclusive licence to Springer-Verlag GmbH Germany, part of Springer Nature 2021

\begin{abstract}
Purpose To analyze the impact of AAD on the severity and mortality of COVID-19 patients and compare clinical outcomes between patients with and without AAD.

Methods In the systematic review and meta-analysis, we searched PubMed, Embase, Web of Science for studies reporting allergic rhinitis, asthma prevalence in COVID-19 patients and compared clinical outcomes, and excluded duplicate publications, reviews, comments, single or few cases reports ( $<100$ cases). We determined the pooled effect estimates using random effect model.

Results Thirty-four studies $(345,091)$ were finally included for the meta-analysis. On the basis of 32 studies $(337,821)$ involving with the severity of COVID-19, we did not find significant association between AAD and the severity of COVID-19 $(p=0.35$, OR $1.10,95 \%$ CI $0.90-1.35)$. Subgroup analysis indicated there was no the variability in the prevalence of AAD among COVID-19 patients in different study designs, disease categories, countries, the definition of severity, and population size of AAD. Based on 21 studies (306,331) involving with the mortality of COVID-19, AAD was significantly associated with the decreased mortality of COVID-19 ( $p<0.05$, OR 0.83, 95\% CI 0.70-0.99). The subgroup analysis showed AAD was not associated with the mortality of COVID-19 in different countries or regions. Based on the population size of AAD, we found AAD within 100 cases was not associated with the mortality of COVID-19 ( $p=0.63$, OR 1.15, 95\% CI 0.65-2.03). Moreover, study design was possible heterogeneity source as the heterogeneity $I^{2}$ was reduced to 0 in prospective studies. Conclusion The preexisting AAD was not inclined to deteriorate the course of COVID-19. The prevalence of AAD was not associated with the severity of COVD-19 patients and inclined to be significantly associated with the decreased mortality risk of COVID-19.
\end{abstract}

Keywords COVID-19 $\cdot$ Allergic rhinitis $\cdot$ Asthma $\cdot$ Epidemiology $\cdot$ Prognosis

\section{Introduction}

The pandemic of coronavirus disease 2019 (COVID-19), caused by the severe acute respiratory syndrome coronavirus 2 (SARS-CoV-2), has rapidly spread around the world since December 2019 and posed a great challenge to worldwide public health. As of April 14, 2021, there have been more than 136,742,018 confirmed cases, including 2,947,423 deaths reported by the World Health Organization [1].

Currently, a variety of risk factors have been identified to be associated with the severity and mortality of COVID-19,

Wei Ming

mw_mingwei@163.com

1 Department of Otolaryngology, Renmin Hospital of Wuhan University, Wuhan 430060, Hubei, China such as older age, male sex, comorbidities, and metabolic abnormalities. Allergic rhinitis (AR) and asthma are often co-occurred and may share common immune pathogenic mechanisms such as type 2 inflammation. AR is one of the most common disorders of nose and affects $10 \%$ to $40 \%$ of the population [2]. The continuity of nasal cavity and bronchus in anatomical structure and physiological function determines intimate relationship between AR and asthma. AR and asthma are 'the one airway, the one disease.' Therefore, we included the studies involving with AR and asthma, as a whole of allergic airway disease (AAD) for better understanding the course of COVID-19.

The association between AAD and the severity and mortality of COVID-19 is largely unknown. Patients with AR and asthma have defect antiviral immune responses and a tendency of exacerbation elicited by familiar respiratory 
viruses. Thus, AAD was proposed to potentially confer increased risk for COVID-19 in the early stage of the pandemic [3-6]. However, adverse evidences showed a low prevalence of asthma among patients with COVID19, because of a potential TH2-mediated protection from COVID-19 in patients with asthma [7,8].

Whether AAD is associated with the severity and mortality of COVID-19 is still controversial. In addition, it remains debatable whether patients with AAD are subject to a more severe pathological process and worse prognosis compared with patients without AAD. A better understanding of the relationship between AAD and COVID-19 may provide new insights of the disease essence. Therefore, we conducted a systematic review and meta-analysis of studies to report the prevalence of comorbid AAD among patients with COVID19 and further performed subgroup analyses based on study design, the disease categories, the geographical regions, and population size of AAD. We also compared clinical outcomes between patients with and without AAD.

\section{Methods}

\section{Search strategy and selection criteria}

This systematic review and meta-analysis were performed following the Preferred Reporting Items for Systematic Reviews and Meta-Analyses guidelines. The protocol was registered in PROSPERO (CRD42021228815). We searched relevant studies in PubMed, Embase, Web of Science with the Mesh terms and free words, 'allergic airway diseases,' 'allergic airway disorders,' 'AR,' or 'asthma' AND 'novel coronavirus' or 'coronavirus disease 2019' or 'SARS-CoV-2 Infection' or 'COVID-19'on Dec 20, 2020 (update on March 31, 2021) in English language.

Studies were included if they fulfilled the following entry criteria: (a) patients were confirmed with COVID-19 infection; (b) provided data of AR or asthma with severe or nonsevere patients or between death and survivals. Exclusion criteria were as follows: (a) studies which did not provide the prevalence of AR or asthma; (b) studies without comparisons (severe versus non-severe patients, death versus survival); (c) abstracts, one case or few cases reports $(<100$ cases), review articles, comments.

We extracted the following data: the name of the first author, country where the study was conducted, size of the cohort, numbers of males or females, ages, and clinical outcomes. The severity of the disease was mainly determined based on symptom (e.g., patients required intubation and mechanical ventilation, with acute respiratory distress syndrome, hospitalization, or admitted to intensive care unit).

Because all studies but 2 were retrospective observational studies, the quality of studies in each was evaluated using the Newcastle-Ottawa Scale (NOS) by two investigators (Ming W and Zuo JJ). A total score of $\geq 7$ indicated a high-quality study, whereas a total score of $<7$ were considered as a low-quality study. In the GRADE system, observational studies start as low-quality evidence. Five factors (risk of bias, imprecision, inconsistency, indirectness, and publication bias) may cause rating down the quality of evidence and three factors (large effect, dose response, and if residual confounding is probably to decrease rather than increase the magnitude of effect) may cause rating up [9].

The literature search, study selection, and data extraction were independently conducted by two authors (Ming $\mathrm{W}$ and Zuo JJ). Any disagreements were resolved by consensus or by a third author (Han JB). Review Manager 5.3 (Cochrane Collaboration) and Stata 16.0 (Stata Corp) were used to pool useful data and calculate odds ratios (ORs) and 95\% confidence intervals (95\% CI). Heterogeneity among combined study results was quantified with Cochran's Q test and the $\mathrm{I}^{2}$ statistic, with values of less than $25 \%, 25 \%$ to $50 \%$, and greater than $50 \%$ represented low, moderate, and high heterogeneity, respectively. Considering the inter-study heterogeneity, a random-effects model was adopted to estimate the pooled effect for a more conservative estimate of the $95 \%$ CI. Sensitivity analysis and publication bias were performed to evaluate the stability of the meta-analysis by Stata 16.0, and $p<0.05$ was considered statistically significant.

\section{Results}

\section{Study selection}

The initial search retrieved 662 results from PubMed, 472 from Web of Science Core Collection, 1,187 from Embase and 28 from other resources. All articles identified in the databases were imported into the Endnote X9 software for management and screening. After removing duplicates, there were 1602 articles for further screening. By reviewing the titles, abstracts, and key terms related to allergic airway disease for further screening, 637 articles were identified to be potentially relevant and then assessed for eligibility. After removing the review articles, conference abstracts, expert opinions, comments, case reports, or studies without comparisons, 23 articles met all the inclusion criteria for quantitative synthesis for having calculable risk estimate. On the second search, the same protocol was followed and another 11 articles were identified. The detailed flowchart is shown in Fig. 1. A total of 34 studies were included in later analysis of the association between AAD and the severity and mortality of COVID-19[10-43]. 


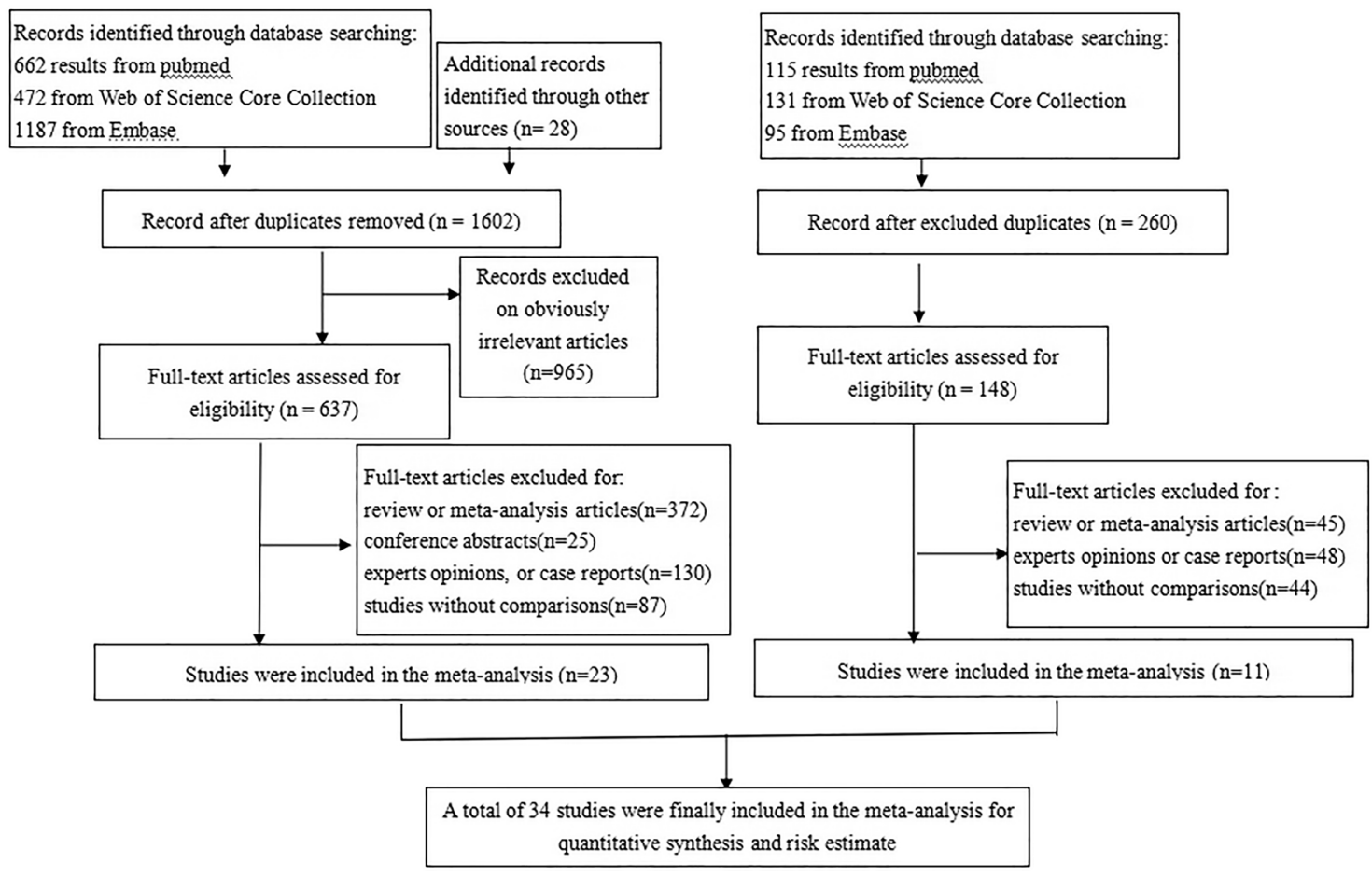

Fig. 1 Flow diagram of the number of studies screened and included in the meta-analysis

\section{Study characteristics}

Detailed description of key characteristics for the 34 included studies is shown in Table 1. In brief, 15 (44.1\%) studies were implemented in America, 8 (23.5\%) were in Asia and 11 (32.4\%) were in Europe. With regard to study design, two articles (Beurnier N and Bloom C) were prospective cohort studies, and others were retrospective observational studies.

For the reported allergic diseases, four groups (Bloom C, Ho KS, Lokken EM, and Yang JM) were conducted a multicenter cohort study for estimating the prevalence and comparison of AAD in COVID-19 patients. For disease categories, 3 were involved with AR, and 32 articles were involved with asthma.

\section{Ascertainment of cases and controls}

For ascertainment of AR and asthma, 16 studies were based on the medical records, 10 were based on International Classification of Diseases edition 10/9 (ICD-10/9), 5 were based on Global Initiative for Asthma (GIFA), one was based on National Heart Lung and Blood Institute's Guidelines for the Diagnosis and Management of Asthma and GINA guidelines, one was based on the Lung function tests, bronchodilation test, and methacholine concentration provoking a $20 \%$ fall in FEV1, and one was based on the nasal symptoms, aeroallergen sensitization noted on SPT or allergen-specific IgE, respiratory symptoms, and pulmonary function tests.

For the definition of severity of COVID-19, 16 studies were based on the admission to ICU, 7 were based on hospitalization, 2 were based on the admission to ICU or death, 1 was based on American Thoracic Society guidelines for community-acquired pneumonia, 1 was based on World Health Organization interim guidance, 1 was based on ARDS, 1 was based on intubations, and the other 3 studied were based on mechanical ventilation. Of all included studies, 26 studies provided the total age information. (Six were mean and 20 were median.)

\section{Quality of studies}

The overall quality of the available literature was moderate with Newcastle-Ottawa Scale scores ranging from 6 to 9. The quality of the included articles was evaluated and presented in Table 2. There were 5 articles (14.7\%) with total scores of 6 points, 12 articles $(35.3 \%)$ with 7 points, 14 articles (41.2\%) with 8 points, and 3 articles (8.8\%) with 9 points.

\section{Data synthesis and meta-analysis}

Altogether, 345,091 participants in 34 studies were entry in the meta-analysis. Of which, 337,821 participants were 


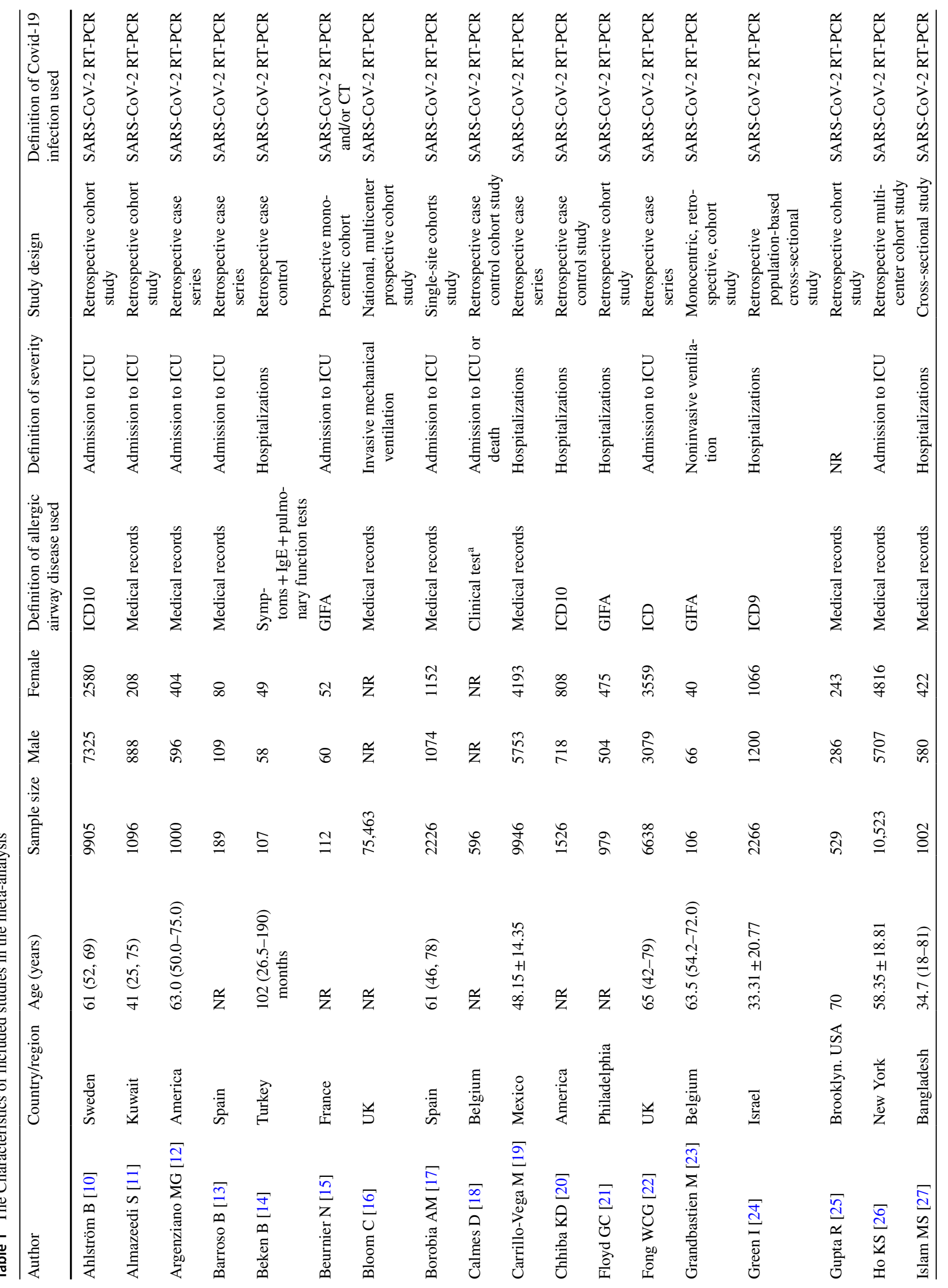




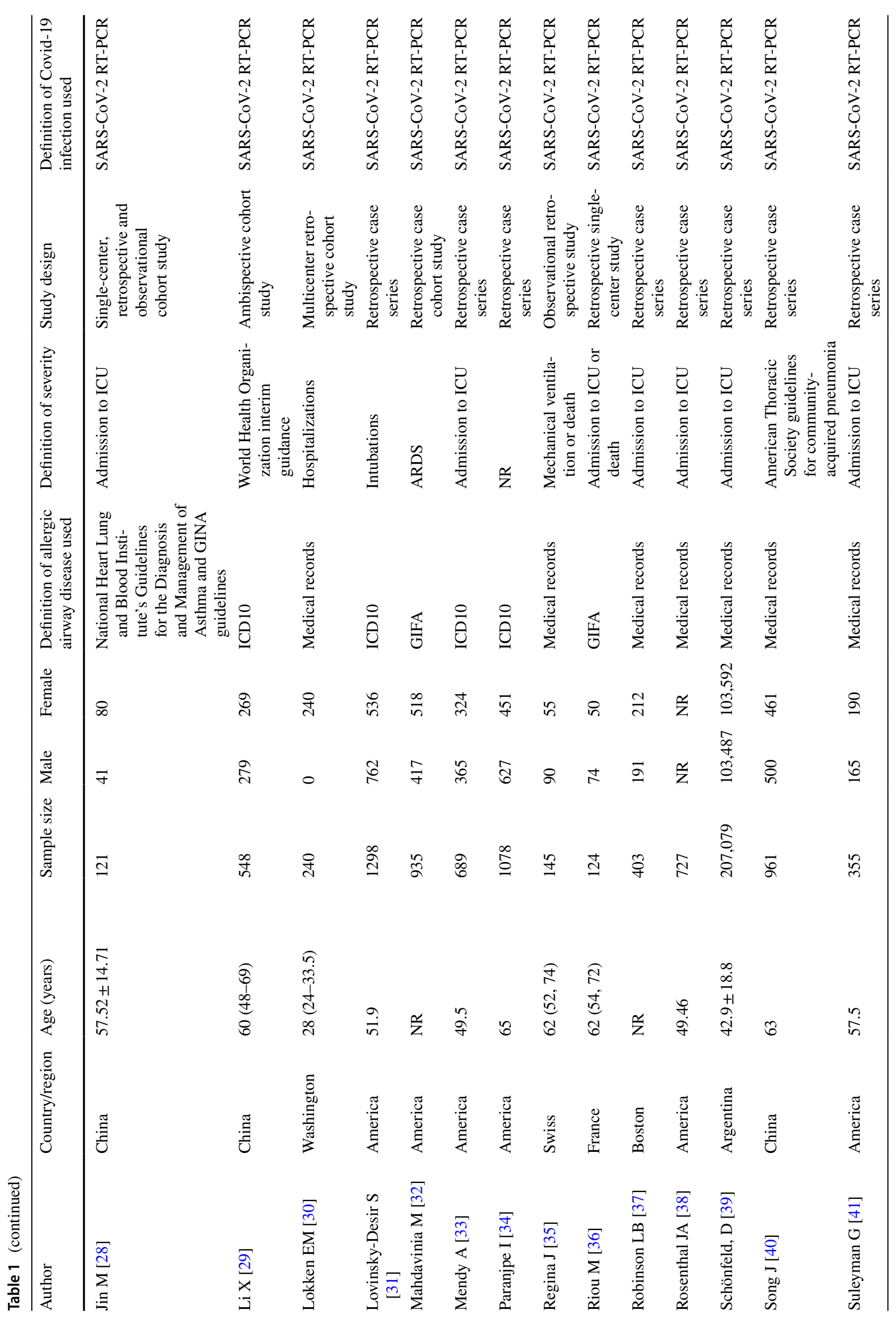




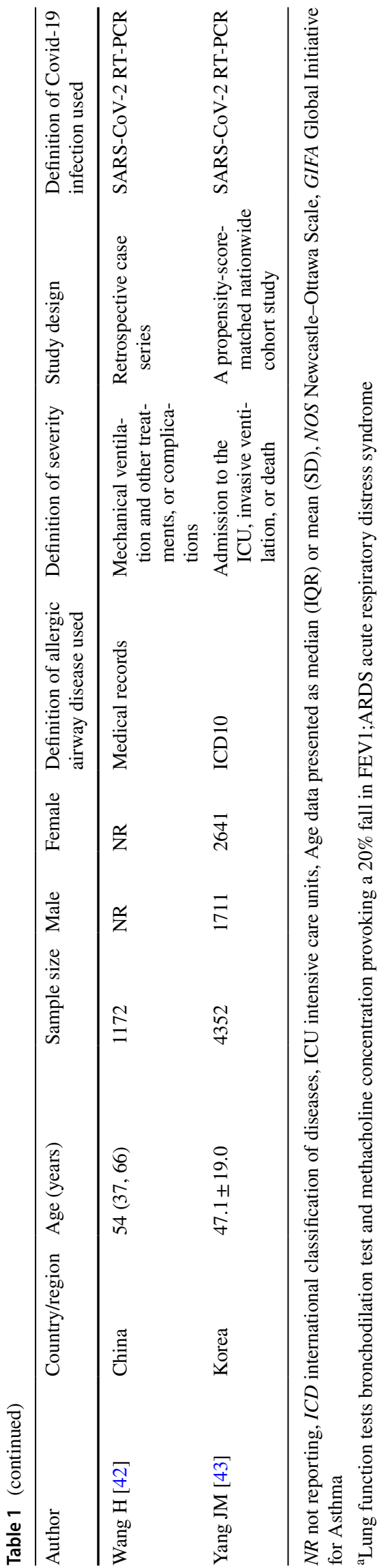

entered in the meta-analysis of the severity of AAD on COVID-19 in 32 studies. By combining 32 studies reporting the outcomes of severity among confirmed COVID-19 patients with and without AAD, there were no significant statistics of relationship between AAD and severity of COVID-19 (OR 1.10, 95\% CI 0.90-1.35, $p=0.35, I^{2}=89 \%$ ), as in Fig. 2.

For the heterogeneity sources of literature synthesis, 32 studies were stratified by study design, various disease categories, countries and population size of AAD. Whether AAD affected the course of COVID-19, we analyzed the relation of $\mathrm{AR}$ and asthma patients with the severity of COVID-19. The results showed that AR and asthma were not significantly associated with the severity of COVID-19 (OR $0.89,95 \%$ CI $0.53-1.47, p=0.64$; OR $1.18,95 \%$ CI $0.90-1.53, p=0.23$, respectively) (see Figure E1 in this article's Online Repository at www.jaci-inpractice.org).

As for the study design, we found that there were no significant association between AAD and the severity of COVID-19 whether in the prospective studies or in the retrospective studies (OR $0.92,95 \% \mathrm{CI} 0.41-2.08, p=0.84$; OR $1.11,95 \%$ CI $0.87-1.42, p=0.39$ ) as in Fig. 3A, B. Subgroup analyses across countries or regions showed that $I^{2}$ was $79 \%$ in America (OR 0.97, 95\% CI 0.77-1.22, $p=0.78$ ), $72 \%$ in Asia (OR 1.10, 95\% CI 0.93-1.30, $p=0.27$ ) and $92 \%$ in Europe (OR 1.06, 95\% CI 0.66-1.70, $p=0.80$ ). No significant association between AAD and severity of COVID-19 was found in different countries or regions, as in Table 3 (see Figure E1 in this article's Online Repository at www. jaci-inpractice.org).

Based on the population size of AAD, we divided into 2 groups, one group within 100 cases and another over 100 cases. In the two groups, AAD was not associated with the risk of the severity of COVID-19 (OR 1.16, 95\% CI $0.67-2.03, p=0.59$; OR $1.06,95 \%$ CI $0.84-1.33, p=0.63$ ), as in Fig. 3C, D. The detailed results are shown in Table 3.

According to the definition of severity of COVID-19, subgroup analyses showed that there were no significant differences in AAD prevalence between ICU and non-ICU patients (OR 1.29, 95\% CI 0.88-1.89, $p=0.19$ ), hospitalized and non-hospitalized patients (OR 0.89, 95\% CI 0.63.1.25, $p=0.49)$, mechanical ventilation and non-mechanical ventilation patients (OR 1.03, 95\% CI 0.76-1.40, $p=0.85$ ) (see Figure E1 in this article's Online Repository at www.jaciinpractice.org).

Twenty-one studies with 306,331 participants were entry in the meta-analysis of the mortality risk of COVID-19. The comparison of clinical outcomes between patients with and without $\mathrm{AAD}$ showed that there was a significant difference between with and without AAD on the mortality of COVID19 (OR 0.83, 95\% CI 0.70-0.99, $p=0.04$ ), as in Fig. 4A.

Based on the study design, there was significantly decreased mortality risk of AAD on the COVID-19 in 


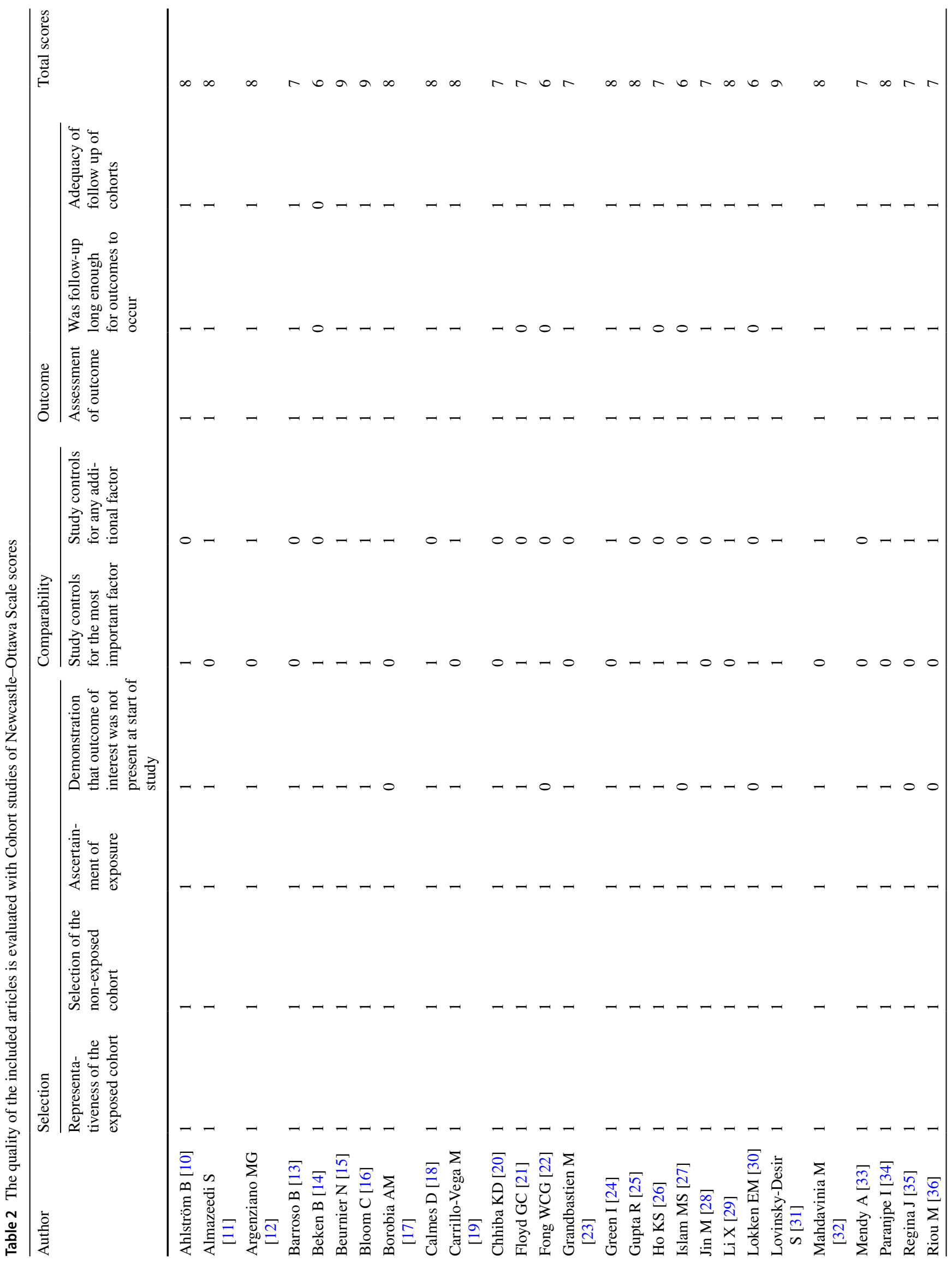




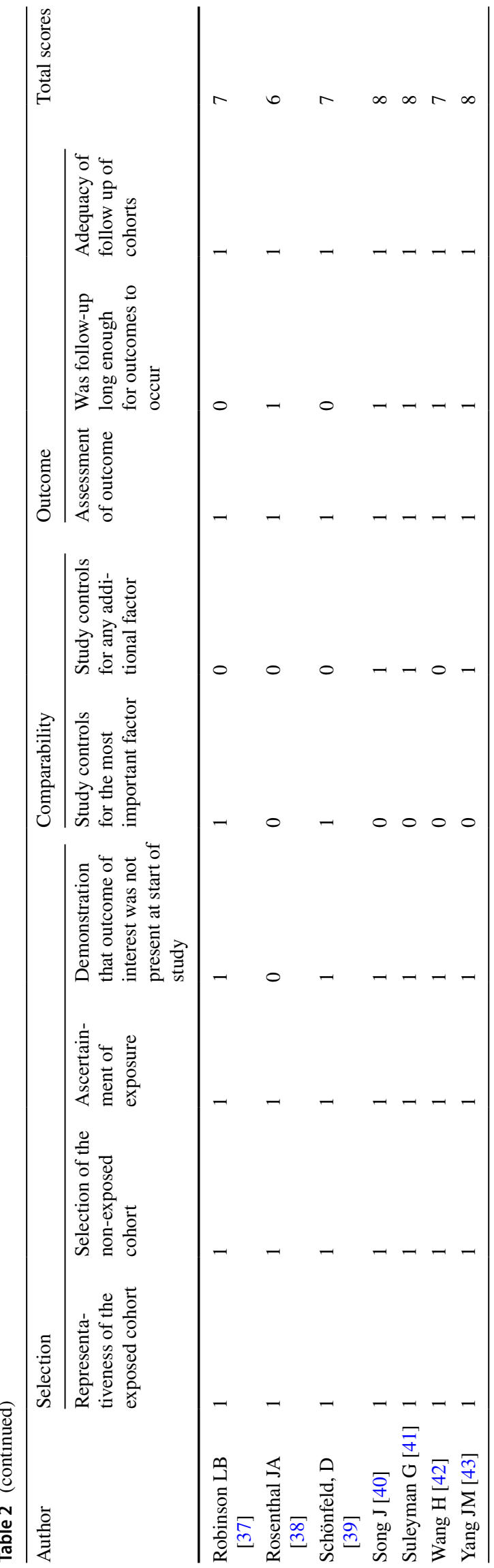

prospective studies (OR $0.73,95 \%$ CI $0.70-0.77, p<0.05$ ), as in Fig. 4B. However, there was no association in retrospective studies (OR 0.88, 95\% CI 0.68-1.15, $p=0.35$ ), as in Fig. 4C. Based on countries or regions, there was not a significant relationship between AAD and mortality risk of COVID-19 in different countries or regions, as in Table 4 (see Figure E1 in this article's Online Repository at www. jaci-inpractice.org).

In the group of $\mathrm{AAD}$ population size in 100 cases, $\mathrm{AAD}$ was not associated with mortality risk of COVID-19 (OR 1.27, 95\% CI 0.73-2.23, $p=0.40$ ), as in Fig. 4D. However, there was significantly statistical association between AAD and the mortality of COVID-19 in the group over 100 cases (OR $0.75,95 \%$ CI $0.63-0.89, p<0.05$ ), as in Fig. 4E.

\section{Sensitivity analysis and heterogeneity}

Visual assessment of the funnel plot did not show the presence of publication bias, and no significant publication bias was detected by Begger test $(p>0.05)$ using Stata 16.0 software. However, there was substantial heterogeneity among AAD studies (Severity: $I^{2}=89 \%$; Mortality: $I^{2}=74 \%$ ).

The high heterogeneity in the meta-analysis for studies on the severity risk in COVID-19 patients with and without AAD was possibly due to the different definition of severity and study design which may have resulted into clinical or methodological sources of heterogeneity. The high heterogeneity of studies on the mortality risk in COVID-19 patients was possibly study design because the heterogeneity $I^{2}$ was reduced to $0 \%$ in prospective studies. After excluding two studies (Almazeedi and Schönfeld) in retrospective studies, the heterogeneity $I^{2}$ was reduced from 74 to $43 \%$. And then excluding another two studies (Ahlström and Gupta), the heterogeneity $I^{2}$ was reduced to 0 . GRADE certainty of findings were low (Table 5).

\section{Discussion}

Recently, with more relevant articles regarding allergic airway disease including AR and asthma, in the severity and mortality of COVID-19 published, the result of this metaanalysis, which was stable on the sensitivity analysis, did not obviously show a worse prognosis of COVID-19 in patients with AAD. To our knowledge, the meta-analysis is the first to make a pooled estimate of AAD-related outcomes, which combined with allergic rhinitis and asthma and based on a larger COVID-19 populations. The meta-analysis showed there was no significant higher prevalence of AAD in COVID-19 patients, who needed hospitalizations, intensive care unit, or mechanical ventilation. Moreover, AAD was significantly associated with the decreased mortality risk of COVID-19. However, we should not neglect the importance 


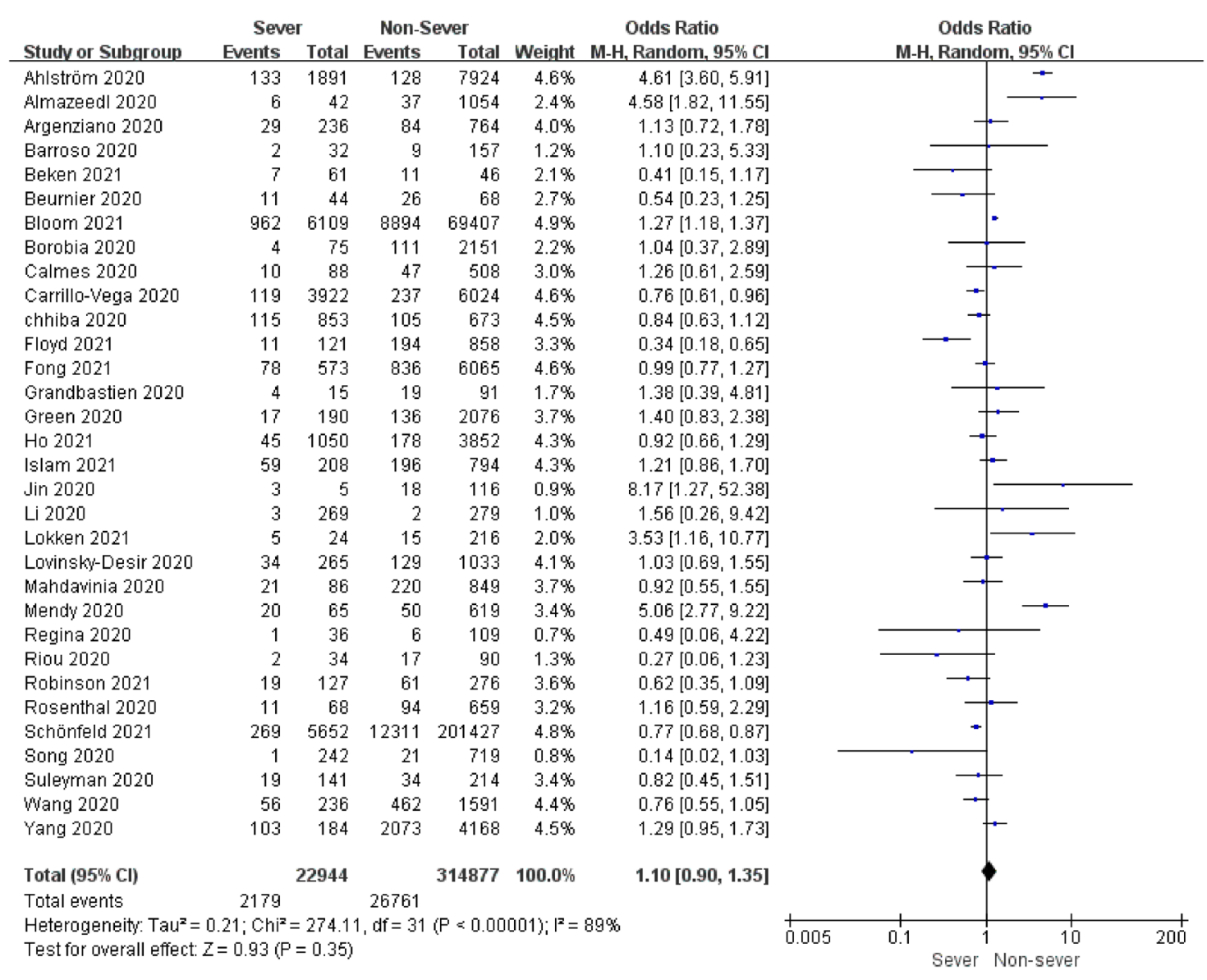

Fig. 2 Forestplot of the severity of comorbid AAD in COVID-19 patients

of tough control of COVID-19 spread and a need for mitigation strategies in patients with preexisting AAD.

To date, the relationship between AAD and the severity and mortality of COVID-19 was controversial. There were 3 studies involving with AR impact on the course of COVID-19, and the pooled estimates showed that AR was not associated with the severity of COVID-19 [14, 42, 43]. The pooled estimates of 32 studies involving with asthma impact on COVID-19 indicated no significant association between asthma and the severity of COVID-19. Our study is based on incorporating more available studies and a larger population. Moreover, the disease category (allergic rhinitis and asthma) was not heterogeneity source of literature synthesis.

A few of public studies showed that asthma and allergic rhinitis were associated with the severity of COVID-19, although of the different criteria of the severity [33, 43, 44]. Moreover, patients with non-allergic asthma had a greater risk and worse clinical outcomes of COVID-19 than patients with allergic asthma. Through the intubation time comparisons, patients with asthma had longer intubation time compared with patients without asthma [32]. The analysis of hospitalization time showed a trend to be longer among patients with a history of asthma compared with patients without asthma aged 50 to 64 years. Green et al. found the prevalence rate of COVID-19 was higher in patients with asthma than in those without asthma aged 5 to 19 years and 20 to 39 years [24]. Perhaps, SARS-CoV-2 itself could potentially exacerbate the pathological process of allergic disease, which could facilitate viral entry and lead to a serious outcome of COVID-19.

However, there were more evidences that patients with severe asthma did not exacerbate the severity of COVID19[14, 18, 23, 45-49]. The severe asthma would not increase the risk of COVID-19 infection and severity [46]. No patient developed cytokine storm or acute respiratory distress syndrome although $3.8 \%$ severe asthma had confirmed COVID19 [47]. The epidemiologic study of COVID-19 in China, which included 44,672 confirmed cases of COVID-19, did not identify asthma as a risk factor of COVID-19 severity [29]. An observational study of risk factors for death showed that $7 \%$ patients with asthma died due to COVID-19. 
A

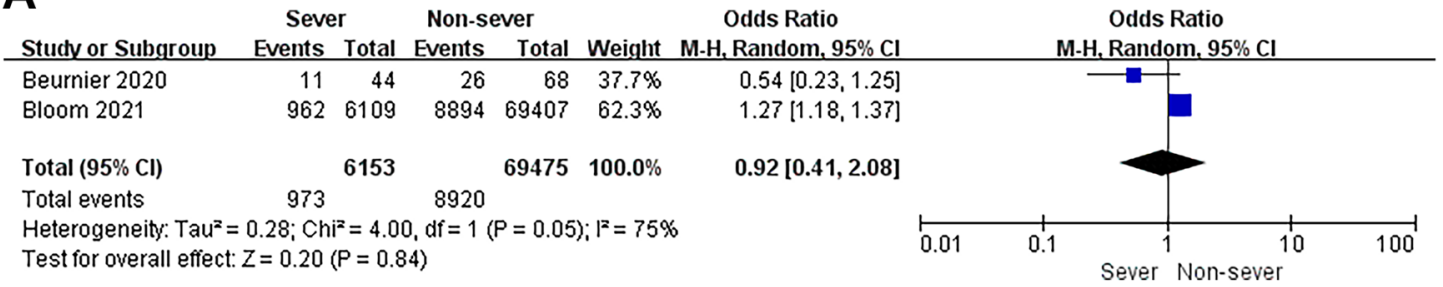

B

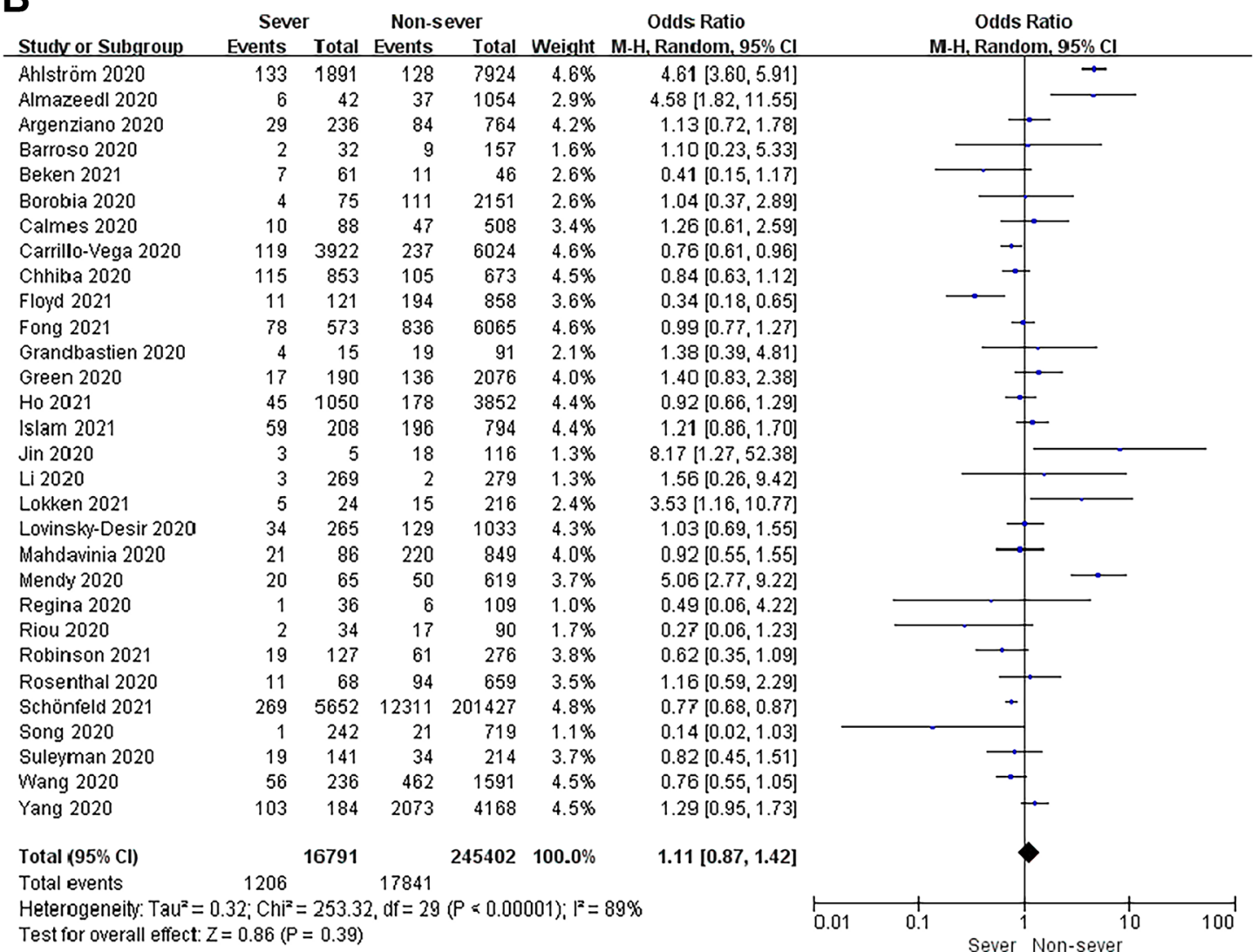

C

Sever Non-sever Odds Ratio

Studver Subgroup Events Total Events Total Weight M.H. Random, 95\% Cl

$\begin{array}{llll}37 & 1054 & 7.7 \% & 4.58[1.82 .11 .55]\end{array}$

Beken 2021

Beurnier 2020

Calmes 2020

Grandbastien 2020

$\operatorname{Jin} 2020$

Li 2020

Lokken 2021

Mendy 2020

Regina 2020

Riou 2020

Robinson 2021

Song 2020

Suleyman 2020

Total $(95 \% \mathrm{Cl})$

Total events

$\begin{array}{rrrrr}2 & 32 & 9 & 157 & 5.5 \% \\ ? & 61 & 11 & 46 & 7.3 \%\end{array}$

Heterageneity: $\operatorname{Tau}^{2}=0.83 ; \mathrm{Chi}^{2}=63.22, \mathrm{df}=14(\mathrm{P}<0.00001) ; \mathrm{I}^{2}=78 \%$

Test for overall effect: $Z=0.53(P=0.59)$

$1.10[0.23,5.33]$

$0.41[0.15,1.17]$

$0.54[0.23,1.25]$

$1.26[0.61,2.59]$

$1.38[0.39,4.81]$

$8.17[1.27,52.38]$

$1.56[0.26,9.42]$

$3.53[1.16,10.7 ?]$

$5.06[2.77,9.22]$

$0.49[0.06,4.22]$

$0.27[0.06,1.23]$

$0.62[0.35,1.09]$

$0.14[0.02,1.03]$

$0.82[0.45,1.51]$

$1.16[0.67,2.03]$

M.H. Random, 95\% Cl

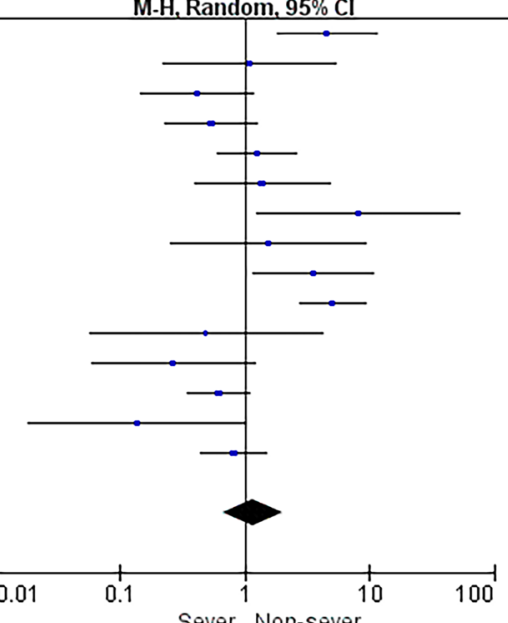

Sever Non-sever

in retrospective studies; C Forestplot of the comparison of the severity of comorbid AAD (within 100 cases) in COVID-19 patients; D Forestplot of the comparison of the severity of comorbid AAD (over 100 cases) in COVID-19 patients 


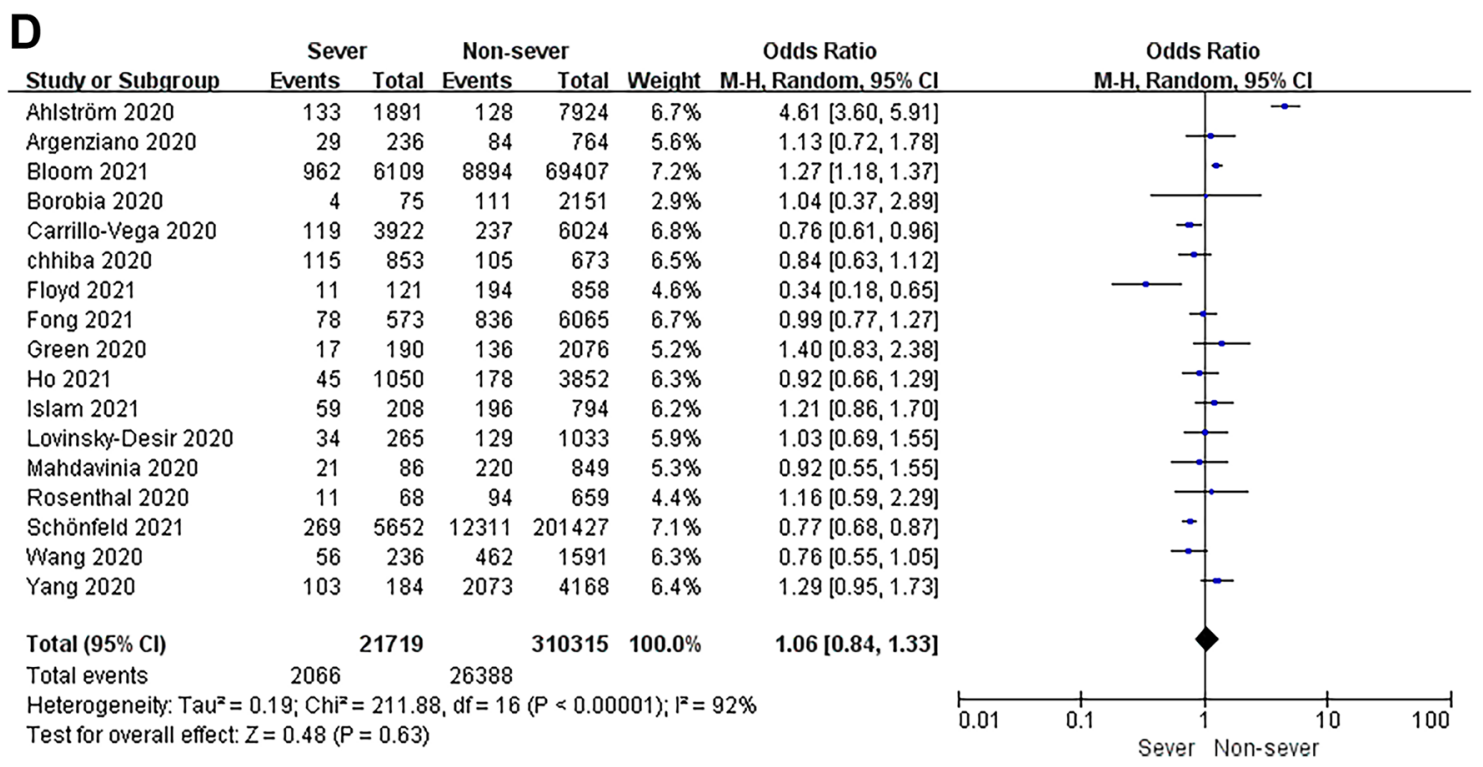

Fig. 3 (continued)

Table 3 The subgroup analysis of AAD relationship with the severity of COVID-19

\begin{tabular}{|c|c|c|c|c|c|}
\hline \multirow[t]{2}{*}{ Subgroup } & \multicolumn{5}{|c|}{ AAD on severity of COVID-19 } \\
\hline & Studies $(N)$ & Participants $(N)$ & $\mathrm{OR}, 95 \% \mathrm{CI}$ & $I^{2}(\%)$ & $p$ value \\
\hline \multicolumn{6}{|l|}{ Study design } \\
\hline Prospective & 2 & 75,628 & $0.92[0.41,2.08]$ & 75 & 0.84 \\
\hline Retrospective & 30 & 262,193 & $1.11[0.87,1.42]$ & 89 & 0.39 \\
\hline \multicolumn{6}{|l|}{ Disease category } \\
\hline Asthma & 30 & 331,642 & $1.13[0.91,1.40]$ & 89 & 0.28 \\
\hline Allergic rhinitis & 3 & 6286 & $0.89[0.53,1.47]$ & 74 & 0.64 \\
\hline \multicolumn{6}{|l|}{ Countries } \\
\hline America & 13 & 230,074 & $0.97[0.77,1.22]$ & 79 & 0.78 \\
\hline Asia & 8 & 12,173 & $1.10[0.93,1.30]$ & 72 & 0.27 \\
\hline Europe & 11 & 95,574 & $1.06[0.66,1.70]$ & 92 & 0.80 \\
\hline \multicolumn{6}{|l|}{ AAD Population Size } \\
\hline$<=100$ & 15 & 5787 & $1.16[0.67,2.0$ & ] 78 & 0.59 \\
\hline$>100$ & 17 & 332,034 & $1.06[0.51,1]$. & ] 92 & 0.63 \\
\hline \multicolumn{6}{|l|}{ Definition of severity } \\
\hline Hospitalization & 7 & 16,066 & $0.89[0.63,1.2$ & ] 75 & 0.49 \\
\hline ICU & 17 & 240,419 & $1.29[0.88,1.8$ & ] 93 & 0.19 \\
\hline Mechanical ventilation & 5 & 78,892 & $1.03[0.76,1$. & 64 & 0.85 \\
\hline Others & 3 & 2444 & $0.71[0.23,2$. & 49 & 0.54 \\
\hline
\end{tabular}

The multivariate analysis confirmed that male gender, older age, cardiopathy, and immunosuppressive disease were predictors of death in patients hospitalized due to COVID-19 infection [18]. One hypothesis is that patients with asthma were more compliant to their treatment and respected social distancing for avoiding the severe pulmonary infection [48].

Theoretically, it seems that impaired mucous members and higher virus load caused by asthma have a potential influence on SARSCoV-2 susceptibility and disease course. However, existing studies have not indicated a high prevalence of asthma among COVID-19 patients [23, 29, 45-50]. ACE2, angiotensin-converting enzyme II, which is the entry receptor for SARS-CoV-2, might be influenced by asthmatic status. Type I IFNs and type II IFNs upregulated the expression of ACE2, SARS-CoV-2 might weaken host antiviral defense and facilitate its entry into target cells. However, the damaged IFN responses in asthmatic patients might reduce the virus invasion through limiting 


\begin{tabular}{|c|c|c|c|c|c|c|}
\hline \multirow{2}{*}{$\begin{array}{l}\text { A } \\
\text { Study or Subgroup }\end{array}$} & \multicolumn{2}{|c|}{ Deaths } & \multicolumn{2}{|c|}{ Survivals } & \multirow{2}{*}{ Weight } & \multirow{2}{*}{$\begin{array}{c}\text { Odds Ratio } \\
\text { M-H, Random, } 95 \% \mathrm{Cl}\end{array}$} \\
\hline & Events & Iotal & Events & Total & & \\
\hline Anlström 2021 & 32 & 346 & 73 & 1198 & $7.4 \%$ & $1.57[1.02,2.42]$ \\
\hline Almazeedl 2020 & 4 & 19 & 39 & 1037 & $2.0 \%$ & $3.10[2.25,22.38]$ \\
\hline Barroso 2020 & 2 & 24 & 9 & 165 & $1.1 \%$ & $1.58[0.32,7.77]$ \\
\hline Beurnier 2020 & 3 & 13 & 34 & 99 & $1.5 \%$ & $0.57[0.15,2.22]$ \\
\hline Bloom 2021 & 2545 & 23302 & 3190 & $5025 ?$ & $13.0 \%$ & $0.73[0.70,0.77]$ \\
\hline Borobia 2020 & 17 & 460 & 98 & 1766 & $6.1 \%$ & $0.65[0.39,1.10]$ \\
\hline Calmes 2020 & 4 & 87 & 53 & 509 & $2.4 \%$ & $0.41[0.15,1.18]$ \\
\hline Carrillo-Vega 2020 & 31 & 963 & 325 & 8983 & $8.3 \%$ & $0.89[0.61,1.29]$ \\
\hline Chniba 2020 & 8 & 72 & 212 & 1454 & $3.9 \%$ & $0.73[0.35,1.55]$ \\
\hline Gupta 2021 & 21 & 246 & 9 & 271 & $3.6 \%$ & $2.72[1.22,6.05]$ \\
\hline Ho 2021 & 54 & 1408 & 169 & 3494 & $9.3 \%$ & $0.78[0.57,1.07]$ \\
\hline $\operatorname{Jin} 2020$ & 1 & 3 & 20 & 118 & $0.5 \%$ & $2.45[0.21,28.34]$ \\
\hline Lovinsky-Desir 2020 & 9 & 110 & 154 & 1188 & $4.3 \%$ & $0.60[0.30,1.21]$ \\
\hline Mahdavinia 2020 & 2 & 18 & 239 & 917 & $1.3 \%$ & $0.35[0.08,1.55]$ \\
\hline Mendy 2020 & 3 & 26 & $6 ?$ & 663 & $1.8 \%$ & $1.16[0.34,3.97]$ \\
\hline Paranjpe 2020 & 23 & 310 & 61 & 768 & $6.4 \%$ & $0.93[0.56,1.53]$ \\
\hline Robinson 2021 & 7 & 45 & 73 & 358 & $3.3 \%$ & $0.72[0.31,1.68]$ \\
\hline Rosenthal 2020 & 10 & 61 & 95 & 666 & $4.2 \%$ & $1.18[0.58,2.40]$ \\
\hline Schönfeld 2021 & 396 & 10913 & 12184 & 191166 & $12.6 \%$ & $0.55[0.50,0.61]$ \\
\hline Song 2020 & 1 & 159 & 21 & 802 & $0.7 \%$ & $0.24[0.03,1.76]$ \\
\hline Wang 2020 & 18 & 98 & 500 & 1729 & $6.2 \%$ & $0.55[0.33,0.93]$ \\
\hline Total $(95 \% \mathrm{Cl})$ & & 38683 & & 267648 & $100.0 \%$ & $0.83[0.70,0.99]$ \\
\hline Total ev & 3191 & & & & & \\
\hline
\end{tabular}

Heterogeneity: Tau $^{2}=0.06 ; \mathrm{Chi}^{2}=75.99, \quad \mathrm{df}=20(\mathrm{P}<0.00001) ; \mathrm{F}^{2}=74 \%$

Test for overall effect: $Z=2.05(P=0.04)$

B

Death Survival Odds Ratio $\quad$ Odds Ratio

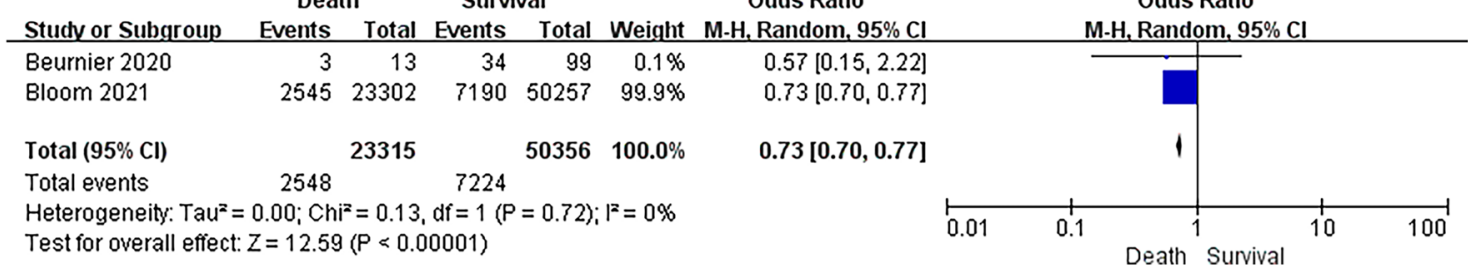

C

Death Survival

Odds Ratio

Odds Ratio

\begin{tabular}{|c|c|c|c|c|c|c|c|c|c|c|c|}
\hline Study or Subgroup & Events & Total & Events & Total & Weight & $\mathrm{H}$, Random, $95 \% \mathrm{Cl}$ & & & I-H. Randol & $\mathrm{m}, 95 \% \mathrm{Cl}$ & \\
\hline Ahlström 2021 & 32 & 346 & 73 & 1198 & $7.8 \%$ & $1.57[1.02,2.42]$ & & & & & \\
\hline Almazeedl 2020 & 4 & 19 & 39 & $107 ?$ & $3.4 \%$ & $7.10[2.25,22.38]$ & & & & & \\
\hline Barroso 2020 & 2 & 24 & 9 & 165 & $2.1 \%$ & $1.58[0.32,7.77]$ & & & & & \\
\hline Borobia 2020 & 17 & 460 & 98 & 1766 & $7.1 \%$ & $0.65[0.39,1.10]$ & & & $\rightarrow$ & & \\
\hline Calmes 2020 & 4 & 87 & 53 & 509 & $3.8 \%$ & $0.41[0.15,1.18]$ & & & & & \\
\hline Carrillo-Vega 2020 & 31 & 963 & 325 & 8983 & $8.2 \%$ & $0.89[0.61,1.29]$ & & & & & \\
\hline Chniba 2020 & 8 & 72 & 212 & 1454 & $5.4 \%$ & $0.73[0.35,1.55]$ & & & $\rightarrow$ & 5 & \\
\hline Gupta 2021 & 21 & 246 & 9 & 271 & $5.1 \%$ & $2.72[1.22,6.05]$ & & & & & \\
\hline Ho 2021 & 54 & 1408 & 169 & 3494 & $8.7 \%$ & $0.78[0.57,1.07]$ & & & $\rightarrow$ & & \\
\hline $\operatorname{Jin} 2020$ & 1 & 3 & 20 & 118 & $1.0 \%$ & $2.45[0.21,28.34]$ & & & & & \\
\hline Lovinsky-Desir 2020 & 9 & 110 & 154 & 1188 & $5.8 \%$ & $0.60[0.30,1.21]$ & & & & & \\
\hline Mahdavinia 2020 & 2 & 18 & 239 & $91 ?$ & $2.4 \%$ & $0.35[0.08,1.55]$ & & & & - & \\
\hline Mendy 2020 & 3 & 26 & 67 & 663 & $3.1 \%$ & $1.16[0.34,3.97]$ & & & & & \\
\hline Paranjpe 2020 & 23 & 310 & 61 & 768 & $7.3 \%$ & $0.93[0.56,1.53]$ & & & & - & \\
\hline Robinson 2021 & 7 & 45 & 73 & 358 & $4.8 \%$ & $0.72[0.31,1.68]$ & & & & - & \\
\hline Rosenthal 2020 & 10 & 61 & 95 & 666 & $5.7 \%$ & $1.18[0.58,2.40]$ & & & & & \\
\hline Schönfeld 2021 & 396 & 10913 & 12184 & 191166 & $9.8 \%$ & $0.55[0.50,0.61]$ & & & - & & \\
\hline Song 2020 & 1 & 159 & 21 & 802 & $1.4 \%$ & $0.24[0.03,1.76]$ & & & & & \\
\hline Wang 2020 & 18 & 98 & 500 & 1729 & $7.1 \%$ & $0.55[0.33,0.93]$ & & & & & \\
\hline Total $(95 \% \mathrm{Cl})$ & & 15368 & & 217292 & $100.0 \%$ & $0.88[0.68,1.15]$ & & & & & \\
\hline Total events & 643 & & 14401 & & & & & & & & \\
\hline $\begin{array}{l}\text { Heterogeneity: Tau }= \\
\text { Test for overall effect: }\end{array}$ & $\begin{array}{l}8 ; \mathrm{Chi}^{2} \\
0.92\langle\mathrm{P}\end{array}$ & $\begin{array}{l}=69.64, \\
=0.35)\end{array}$ & $=18$ & 0.00 & $i^{2}=$ & & .01 & 0.1 & & 10 & 100 \\
\hline
\end{tabular}

Fig. 4 Forestplot of the mortality of comorbid AAD in COVID19 patients and subgroup analysis. A Forestplot of the comparison of the mortality of all comorbid AAD in COVID-19 patients; B Forestplot of the comparison of the mortality of comorbid AAD in COVID-19 in prospective studies; C Forestplot of the comparison of the mortality of comorbid AAD in COVID-19 in retrospective studies; D Forestplot of the comparison of the mortality of comorbid AAD (within 100 cases) in COVID-19 patients; E Forestplot of the comparison of the mortality of comorbid AAD (over 100 cases) in COVID-19 patients 


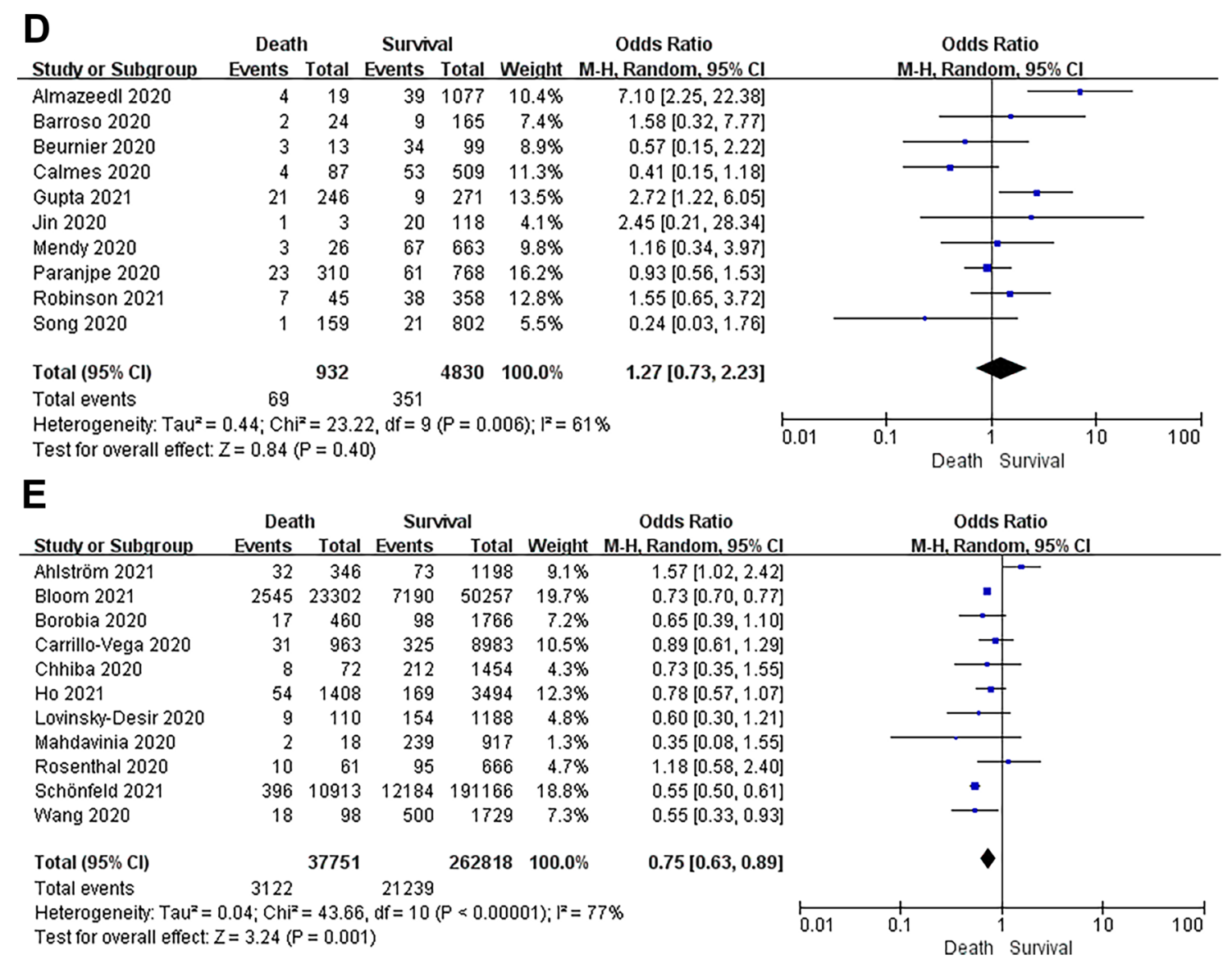

Fig. 4 (continued)

Table 4 The subgroup analysis of AAD relationship with the mortality of COVID-19

\begin{tabular}{lccccc}
\hline Subgroup & Studies $(N)$ & \multicolumn{4}{l}{ AAD on mortality of COVID-19 } \\
\cline { 4 - 6 } & & Participants $(N)$ & OR, 95\% CI & $I^{2}(\%)$ & $p$ value \\
\hline Study design & 2 & 73,671 & $0.73[0.70,0.77]$ & 0 & $<0.05^{*}$ \\
$\quad \begin{array}{l}\text { Prospective } \\
\text { Retrospective }\end{array}$ & 19 & 232,660 & $0.88[0.68,1.15]$ & 74 & 0.35 \\
Countries & & & & & \\
America & 11 & 224,100 & $0.83[0.63,1.08]$ & 68 & 0.16 \\
Asia & 4 & 4005 & $1.24[0.24,6.38]$ & 84 & 0.80 \\
Europe & 6 & 78,226 & $0.83[0.57,1.22]$ & 64 & 0.34 \\
AAD population size & & & & \\
$\quad<=100$ & 10 & 5762 & $1.27[0.73,2.23]$ & 77 & 0.40 \\
$>100$ & 11 & 300,569 & $0.75[0.63,0.89]$ & 61 & $<0.05^{*}$ \\
\hline
\end{tabular}

* indicated that the difference between two groups was statistically significant the ACE2 expression [51]. Type 2 immune response, including clustered eosinophils and type 2 cytokines, might protect against COVID-19. Furthermore, conventional therapeutics for asthma might also reduce the risks of asthmatics suffering infection of the virus through alleviating inflammation or enhancing antiviral defense [51,
52]. Therefore, it should be further studied whether type 2 immune response contributes to the protection of AAD patients against COVID-19.

This meta-analysis indicated that there was significantly decreased mortality risk of AAD impact on COVID-19 patients (OR 0.83, 95\% CI 0.70-0.99, $p=0.04, I^{2}=74 \%$ ). 
Table 5 GRADE evidence profile of all observational studies included in the systematic review

\begin{tabular}{lllllll}
\hline Outcome measure & Studies $(N)$ & Risk of bias & Imprecision & Inconsistency & Indirectness & $\begin{array}{c}\text { Publication bias } \\
\text { Certainty } \\
\text { of evi- } \\
\text { dence }\end{array}$ \\
\hline Asthma & $32^{\text {a }}$ & No serious risk & $\begin{array}{c}\text { No serious impreci- } \\
\text { sion }\end{array}$ & $\begin{array}{c}\text { No serious incon- } \\
\text { sistency }\end{array}$ & $\begin{array}{c}\text { No serious indirect- } \\
\text { ness }\end{array}$ & $\begin{array}{c}\text { Undetected } \\
\text { Low } \\
\text { Allergic rhinitis }\end{array}$ \\
$3^{\text {a }}$ & No serious risk & $\begin{array}{c}\text { No serious impreci- } \\
\text { sistency }\end{array}$ & $\begin{array}{c}\text { No serious indirect- } \\
\text { ness }\end{array}$ & Undetected & Low \\
\hline
\end{tabular}

${ }^{\mathrm{a}}$ One study (Beken B) was involved with the allergic rhinitis and asthma

Subgroup analysis indicated that there were no significant prevalence of AAD mortality in COVID-19 patients in different countries or regions. We found that in two prospective studies, AAD was significantly associated with the decreased mortality risk of COVID-19 patients, and the heterogeneity $I^{2}$ was 0 . But in retrospective studies, the heterogeneity $I^{2}$ was reduced from 74 to $43 \%$ after excluding two studies (Almazeedi S and Schönfeld D). And then excluding another two studies (Ahlström B and Gupta R), the heterogeneity $I^{2}$ was reduced to 0 . Therefore, the four studies (Almazeedi S, Schönfeld D, Ahlström B, and Gupta R) were possible main heterogeneity sources in retrospective studies.

Based on the population size of AAD, subgroup analysis (AAD cases within 100 cases) indicated that AAD was not associated with the mortality risk of COVID-19 patients (OR 1.27, 95\% CI 0.73-2.23, $p=0.40$ ). But in groups over 100 cases, AAD was significantly associated with the mortality risk of COVID-19 (OR 0.75, 95\% CI $0.63-0.89, p<0.05)$. Therefore, the population size of AAD in studies probably influenced the final results of association between AAD and the mortality of COVID19. For acquiring more accurate results and reducing the impact risk of AAD population size on the severity of COVID-19, the researchers should include enough population sizes of AAD cases.

One of the main strengths of our study was that it provided data from a large cohort patients from up-to-date databases and first to make a pooled estimate of AAD-related outcomes, which combined with allergic rhinitis and asthma and based on a larger COVID-19 populations. Moreover, the population size of studied disease would possibly influence the final conclusion. Our meta-analysis has several potential limitations. The included observational studies were subject to potential confounders that might weaken the overall effect estimate. Although we conducted subgroup analysis and sensitivity analysis, the heterogeneity across the studies was substantial and the results based on the analysis were also subjected to limited numbers of studies. The reasons of heterogeneity could be related to methodological quality of bias among studies, different adjusted risk factors used, study design, and severity definition of allergic airway disease.
Data on allergic compositions were lacking in the included studies, hence, cannot be analyzed. Allergic airway disease could include more phenotypes, particularly about whether asthma was allergic or not.

\section{Conclusion}

In conclusion, the results of this study revealed that preexisting allergic airway disease is not inclined to deteriorate the course of COVID-19. Furthermore, AAD was significantly associated with the decreased mortality risk of COVID19 patients. On the basis of data of 345,091 patients with COVID-19 in 34 studies, the analysis showed there were not variability in the prevalence of comorbid allergic airway disease in patients with COVID-19 in different countries or regions. In addition, the population size of allergic airway disease would also influence the study results. More studies are required to search for the pathogenic mechanisms and therapeutic implications.

Supplementary Information The online version contains supplementary material available at https://doi.org/10.1007/s00405-021-07072-1.

Author contributions All persons designated as the authors have participated sufficiently in the work to take public responsibility for the content of the manuscript.

Funding The study was supported by Hubei Provincial Natural Science Foundation (No.2011CBD484).

\section{Declarations}

Conflict of interest The authors declare no conflict of interest.

\section{References}

1. World Health Organization (2021) WHO coronavirus disease (COVID-19) dashboard. 2020. https://covid19.who.int. Accessed April 14th, 2021. 
2. Pawankar R (2014) Allergic diseases and asthma: a global public health concern and a call to action. World Allergy Organ J 7:12. https://doi.org/10.1186/1939-4551-7-12

3. Centers for Disease Control and Prevention (2020) People with certain medical conditions 2020. https://www.cdc.gov/coron avirus/2019-ncov/need-extra-precautions/people-with-medic al-conditions.html. Accessed August 31, 2020.

4. National Health Service (2020) Who's at higher risk from coronavirus. https://www.nhs.uk/conditions/coronavirus-covid-19/ people-athigher-risk/whos-at-higher-risk-from-coronavirus/. Accessed August 31, 2020.

5. Richardson S, Hirsch JS, Narasimhan M et al (2020) Presenting characteristics, comorbidities, and outcomes among 5700 patients hospitalized with COVID-19 in the New York City Area. JAMA 323:2052-2059. https://doi.org/10.1001/jama. 2020.6775

6. Goyal P, Choi JJ, Pinheiro LC et al (2020) Clinical characteristics of Covid-19 in New York City. N Engl J Med 382:2372-2374. https://doi.org/10.1056/NEJMc2010419

7. Zhang JJ, Dong X, Cao YY et al (2020C) clinical characteristics of 140 patients infected with SARS-CoV-2 in Wuhan, China. Allergy 75:1730-41. https://doi.org/10.1111/all.14238

8. Guan W-J, Liang W-H, Zhao Y et al (2020) Comorbidity and its impact on 1590 patients with Covid-19 in China: a nationwide analysis. Eur Respir J 55:2000547. https://doi.org/10.1183/13993 003.00547-2020

9. Guyatt G, Oxman AD, Akl EA et al (2011) GRADE guidelines:1. Introduction-GRADE evidence profiles and summary of findings tables. J Clin Epidemiol 64:383-394. https://doi.org/10.1016/j. jclinepi.2010.04.026

10. Ahlström B, Frithiof R, Hultström M et al (2021) The swedish covid-19 intensive care cohort: risk factors of ICU admission and ICU mortality. Acta Anaesthesiol Scand 65:525-533. https://doi. org/10.1111/aas.13781

11. Almazeedi S, Al-Youha S, Jamal MH et al (2020) Characteristics, risk factors and outcomes among the first consecutive 1096 patients diagnosed with COVID-19 in Kuwait. EClinicalMedicine 24:100448. https://doi.org/10.1016/j.eclinm.2020.100448

12. Argenziano MG, Bruce SL, Slater CL et al (2020) Characterization and clinical course of 1000 patients with coronavirus disease 2019 in New York: retrospective case series. BMJ 369:m1996. https://doi.org/10.1136/bmj.m1996

13. Barroso B, Valverde-Monge M, Cañas Jose A et al (2020) Prevalence, characteristics, and outcome of asthmatic patients with type 2 diseases in hospitalized patients with COVID-19 in Madrid, Spain. J Investig Allergol Clin Immunol 30:382-384

14. Beken B, Ozturk GK, Aygun FD et al (2021) Asthma and allergic diseases are not risk factors for hospitalization in children with coronavirus disease 2019. Ann Allergy Asthma Immunol 126:569-575. https://doi.org/10.1016/j.anai.2021.01.018

15. Beurnier A, Jutant EM, Jevnikar M et al (2020) Characteristics and outcomes of asthmatic patients with COVID-19 pneumonia who require hospitalisation. Eur Respir J 56:2001875. https://doi. org/10.1183/13993003.01875-2020

16. Bloom C, Drake TM, Docherty AB et al (2021) Risk of adverse outcomes in patients with underlying respiratory conditions admitted to hospital with COVID-19: a national, multicentre prospective cohort study using the ISARIC WHO Clinical Characterisation Protocol UK. Lancet Respir Med S2213-2600(21):0001300018. https://doi.org/10.1016/S2213-2600(21)00013-8

17. Borobia AM, Carcas AJ, Arnalich F et al (2020) A cohort of patients with COVID-19 in a Major Teaching Hospital in Europe. J Clin Med 9:1733. https://doi.org/10.3390/jcm9061733

18. Calmes D, Graff S, Maes N et al (2021) Asthma and COPD are not risk factors for ICU stay and death in case of SARS-CoV2 infection. J Allergy Clin Immunol Pract 9:160-169. https://doi. org/10.1016/j.jaip.2020.09.044

19. Carrillo-Vega MF, Salinas-Escudero G, García-Peña C et al (2020) Early estimation of the risk factors for hospitalization and mortality by COVID-19 in Mexico. PLoS ONE 15:e0238905. https://doi. org/10.1371/journal.pone.0238905

20. Chhiba KD, Patel GB, Vu THT et al (2020) Prevalence and characterization of asthma in hospitalized and nonhospitalized patients with COVID-19. J Allergy Clin Immunol 146:307-314.e4. https:// doi.org/10.1016/j.jaci.2020.06.010

21. Floyd GC, Dudley JW, Xiao R et al (2021) Prevalence of asthma in hospitalized and non-hospitalized children with COVID-19. J Allergy Clin Immunol Pract 9:2077-2079.e2. https://doi.org/10. 1016/j.jaip.2021.02.038

22. Fong WCG, Borca F, Phan $\mathrm{H}$ et al (2021) Asthma did not increase in-hospital COVID-19-related mortality in a tertiary UK hospital. Clin Exp Allergy. https://doi.org/10.1111/cea.13855

23. Grandbastien M, Piotin A, Godet J et al (2020) SARS-CoV-2 pneumonia in hospitalized asthmatic patients did not induce severe exacerbation. J Allergy Clin Immunol Pract 8:2600-2607. https://doi.org/10.1016/j.jaip.2020.06.032

24. Green I, Merzon E, Vinker S et al (2021) COVID-19 susceptibility in bronchial asthma. J Allergy Clin Immunol Pract 9:684-692.e1. https://doi.org/10.1016/j.jaip.2020.11.020

25. Gupta R, Agrawal R, Bukhari Z et al (2021) Higher comorbidities and early death in hospitalized African-American patients with Covid-19. BMC Infect Dis 21:78. https://doi.org/10.1186/ s12879-021-05782-9

26. Ho KS, Howell D, Rogers L et al (2021) The relationship between asthma, eosinophilia, and outcomes in coronavirus disease 2019 infection. Ann Allergy Asthma Immunol S1081-1206(21):00139 00143. https://doi.org/10.1016/j.anai.2021.02.021

27. Islam MS, Ferdous MZ, Islam US et al (2021) Treatment, persistent symptoms, and depression in people infected with COVID-19 in Bangladesh. Int J Environ Res Public Health 18:1453. https:// doi.org/10.3390/ijerph18041453

28. Jin M, Chen C, Huang J et al (2020) Clinical characteristics of COVID-19 patients with asthma in Wuhan, China: a retrospective cohort study. J Asthma 30:1-9. https://doi.org/10.1080/02770903. 2020.1850768

29. Li X, Xu S, Yu M et al (2020) Risk factors for severity and mortality in adult COVID-19 inpatients in Wuhan. J Allergy Clin Immunol 146:110-118. https://doi.org/10.1016/j.jaci.2020.04.006

30. Lokken EM, Huebner EM, Taylor GG et al (2021) Disease severity, pregnancy outcomes, and maternal deaths among pregnant patients with severe acute respiratory syndrome coronavirus 2 infection in Washington State. Am J Obstet Gynecol S00029378(21):00033-00038. https://doi.org/10.1016/j.ajog.2020.12. 1221

31. Lovinsky-Desir S, Deshpande DR, De A et al (2020) Asthma among hospitalized patients with COVID-19 and related outcomes. J Allergy Clin Immunol 146:1027-34.e4. https://doi.org/ 10.1016/j.jaci.2020.07.026

32. Mahdavinia M, Foster KJ, Jauregui E et al (2020) Asthma prolongs intubation in COVID-19. J Allergy Clin Immunol Pract 8:2388-2391. https://doi.org/10.1016/j.jaip.2020.05.006

33. Mendy A, Apewokin S, Wells AA et al (2020) Factors associated with hospitalization and disease severity in a racially and ethnically diverse population of COVID-19 Patients. medRxiv. https:// doi.org/10.1101/2020.06.25.20137323

34. Paranjpe I, Russak AJ, De Freitas JK et al (2020) Retrospective cohort study of clinical characteristics of 2199 hospitalised patients with COVID-19 in New York City. BMJ Open 10:e040736. https://doi.org/10.1136/bmjopen-2020-040736.10

35. Regina J, Papadimitriou-Olivgeris M, Burger R et al (2020) Epidemiology, risk factors and clinical course of SARS-CoV-2 infected 
patients in a Swiss university hospital: an observational retrospective study. PLoS ONE 15:e0240781. https://doi.org/10.1371/journ al.pone.0240781

36. Riou M, Marcot C, Canuet M et al (2020) Clinical characteristics of and outcomes for patients with COVID-19 and comorbid lung diseases primarily hospitalized in a conventional pulmonology unit: a retrospective study. Respir Med Res 79:100801. https:// doi.org/10.1016/j.resmer.2020.100801

37. Robinson LB, Fu X, Bassett IV et al (2021) COVID-19 severity in hospitalized patients with asthma: a matched cohort study. J Allergy Clin Immunol Pract 9:497-500. https://doi.org/10.1016/j. jaip.2020.10.021

38. Rosenthal JA, Awan SF, Fintzi J et al (2021) Asthma is associated with increased risk of intubation but not hospitalization or death in coronavirus disease 2019. Ann Allergy Asthma Immunol 126:93-95. https://doi.org/10.1016/j.anai.2020.10.002

39. Schönfeld D, Arias S, Bossio JC et al (2021) Clinical presentation and outcomes of the first patients with COVID-19 in Argentina: results of 207079 cases from a national database. PLoS ONE 16:e0246793. https://doi.org/10.1371/journal.pone.0246793

40. Song J, Zeng M, Wang H et al (2020) Distinct effects of asthma and COPD comorbidity on disease expression and outcome in patients with COVID-19. Allergy 76:483-496. https://doi.org/10. 1111/all.14517

41. Suleyman G, Fadel RA, Malette KM et al (2020) Clinical characteristics and morbidity associated with coronavirus disease 2019 in a series of patients in metropolitan detroit. JAMA Netw Open 3:e2012270. https://doi.org/10.1001/jamanetworkopen.2020. 12270

42. Wang H, Song J, Yao Y et al (2020) Angiotensin-converting enzyme II expression and its implication in the association between COVID-19 and AR. Allergy 76:906-910. https://doi. org/10.1111/all.14569

43. Yang JM, Koh HY, Moon SY et al (2020) Allergic disorders and susceptibility to and severity of COVID-19: A nationwide cohort study. J Allergy Clin Immunol 146:790-798. https://doi.org/10. 1016/j.jaci.2020.08.008

44. Zhu Z, Hasegawa K, Ma B et al (2020) Association of asthma and its genetic predisposition with the risk of severe COVID-19.
J Allergy Clin Immunol 146:327-329.e4. https://doi.org/10.1016/j. jaci.2020.06.001

45. Halpin DMG, Faner R, Sibila O et al (2020) Do chronic respiratory diseases or their treatment affect the risk of SARS-CoV-2 infection? Lancet Respir Med 8:436-438. https://doi.org/10.1016/ S2213-2600(20)30167-3

46. Heffler E, Detoraki A, Contoli M et al (2021) COVID-19 in Severe Asthma Network in Italy (SANI) patients: clinical features, impact of comorbidities and treatments. Allergy 76:887-892. https://doi. org/10.1111/all.14532

47. Haroun-Díaz E, Vázquez de la Torre M, Ruano FJ et al (2020) Severe asthma during the COVID-19 pandemic:clinical observations. J Allergy Clin Immunol Pract 8:2787-2789. https://doi.org/ 10.1016/j.jaip.2020.06.033

48. Kaye L, Theye B, Smeenk I et al (2020) Changes in medication adherence among patients with asthma and COPD during the COVID-19 pandemic. J Allergy Clin Immunol Pract 8:23842385. https://doi.org/10.1016/j.jaip.2020.04.053

49. Lieberman-Cribbin W, Rapp J, Alpert N et al (2020) The impact of asthma on mortality in patients with COVID-19. Chest 158:2290-2291. https://doi.org/10.1016/j.chest.2020.05.575

50. Liu S, Cao Y, Du T et al (2021) Prevalence of comorbid asthma and related outcomes in COVID-19: a systematic review and meta-analysis. J Allergy Clin Immunol Pract 9:693-701. https:// doi.org/10.1016/j.jaip.2020.11.054

51. Liu S, Zhi Y, Ying S (2020) COVID-19 and asthma: reflection during the pandemic. Clin Rev Allergy Immunol 59:78-88. https://doi.org/10.1007/s12016-020-08797-3

52. Skevaki C, Karsonova A, Karaulov A et al (2020) Asthma-associated risk for COVID-19 development. J Allergy Clin Immunol 146:1295-1301. https://doi.org/10.1016/j.jaci.2020.09.017

Publisher's Note Springer Nature remains neutral with regard to jurisdictional claims in published maps and institutional affiliations. 